\section{AN INSTANT BURST OF MINTY FRESHNESS}

Although the human sense of smell is acute, it is difficult for patients to smell their own breath. Therefore, the fear of unpleasant smelling breath remains one of life's most sensitive and significant concerns.

But now your patients can enjoy the reassurance of pleasant breath with $\mathrm{CB} 12$.

Unlike some mouth rinses, $\mathrm{CB} 12$ mouthwash does not just mask oral malodour temporarily. It has a unique patented formula, specifically developed to target and neutralise odorous volatile sulphur compounds (VSCs) with long lasting effects. CB12 mouthwash is clinically proven to neutralise breath for 12 hours after just one rinse.

Rinsing with CB12 mouthwash also helps to enhance your patients' oral hygiene levels. It contains fluoride to strengthen the teeth and prevent cavities as well as highly effective antiplaque agents.

As well as this highly effective mouthwash, there is also the handy CB12 Mouth Spray for an instant burst of minty freshness. It's the perfect supplement to CB12 mouthwash and provides patients with additional confidence wherever they go.

For more information about CB12 and how it could benefit your patients, visit www.cb12.co.uk.

\title{
REVOLUTIONARY SELF-CLEARING MIRROR
}

Nuview is renowned for its range of quality Carl Zeiss dental magnification and illumination systems.

Now, the experienced distributor has extended its product catalogue to include the revolutionary Yirro-plus selfclearing dental mirror - a system that uses controllable airflow to provide the user with nonstop clear sight.

The Yirro-plus can be integrated into most dental chair units by means of spare slot for ease of use. universal adapter or mounted directly into a

The unique design also boasts an ultrareflective surface with a superior smooth multi-layered coating that is repellent to grease and contamination - this provides the user with $99.9 \%$ reflection. The innovation is also autoclavable, requires no maintenance and has an ergonomic grip.

To find out more about the Yirro-plus or other products in the portfolio, contact Nuview on 01453 872266, emailinfo@ nuview-ltd.com or visit

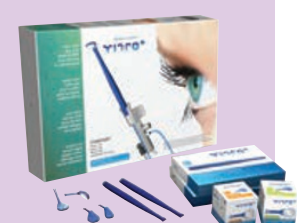

\section{EVERYTHING YOU NEED IN VIBRANT COLOURS}

Whether you're looking to simply inject a little personality into your practice, or you're striving to strengthen your brand, the Vibrenté range of dental consumables are the perfect option.

Available exclusively from Dental Express (a trading division of Surgery Express LLP), the range of bibs, aspirator tips, gloves, masks and more come in a wide range of vibrant, eye-catching colours.

Manufactured to the very highest standards, the range of Vibrenté products includes everything a dental practice needs to provide excellent, personalised service.

If you want your dental practice to stand out from the crowd, consider the Vibrenté range. Contact the expert team from Dental Express to find out more. Visit www.dental-express.co.uk, call 0800707 6212 or email web@dental-express.co.uk.

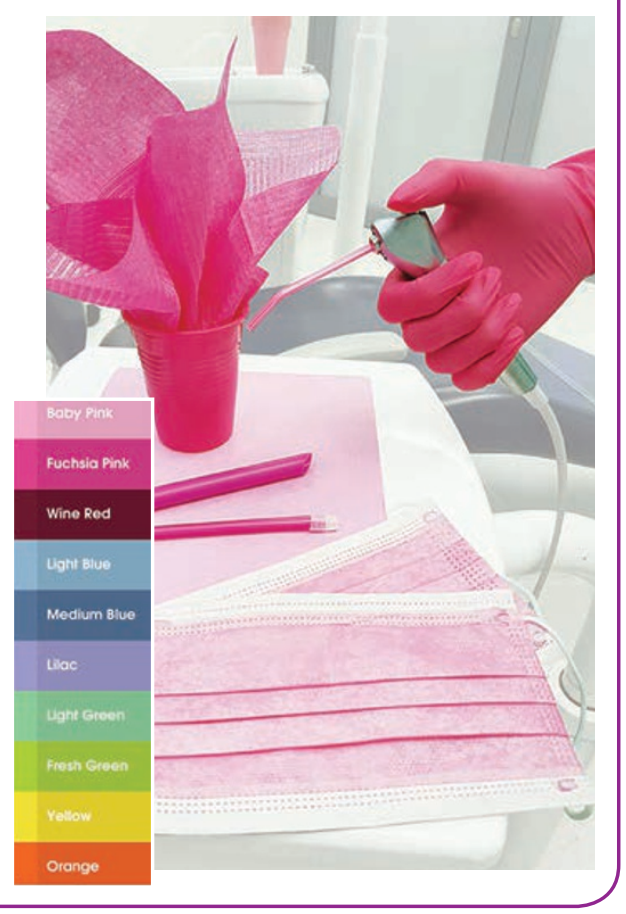

PRESERVING THE LIFE OF YOUR UNIT

Dürr Dental invented the modern day suction system so have a wealth of experience to draw on when it comes to maintenance. To preserve the life of your unit they offer the following tips (based on over 50 years of experience):

1. Aspirate at least one glass of water through the spittoon and the suction hose after every patient to remove blood, saliva and dentine residue

2. Use cold water to mix disinfectant as hot water inactivates many disinfectant components and tends to create foam and cause coagulation when combined with blood

3. Just as with household appliances, limescale can damage components. Depending on water hardness, use MD555 cleaner at least once a week

4. Use only foam-free products intended for the job - never use household cleaning agents in the suction unit

5. Never mix products as this can neutralise the disinfectants

6. Do not use the suction unit to vacuum drawers!

7. Carry out the recommended maintenance.

Dürr Dental are the only supplier of suction systems who also manufacturer cleaning solution. Their Orotol range is the leading brand of suction disinfectant in the world. It boasts an extraordinary cleaning power and is foam-free making it popular with dental nurses. The suction I range is available as either a concentrated powder or as a liquid, both of which have an environmentally friendly composition and a pleasant odour.

For more information call 01536526740.

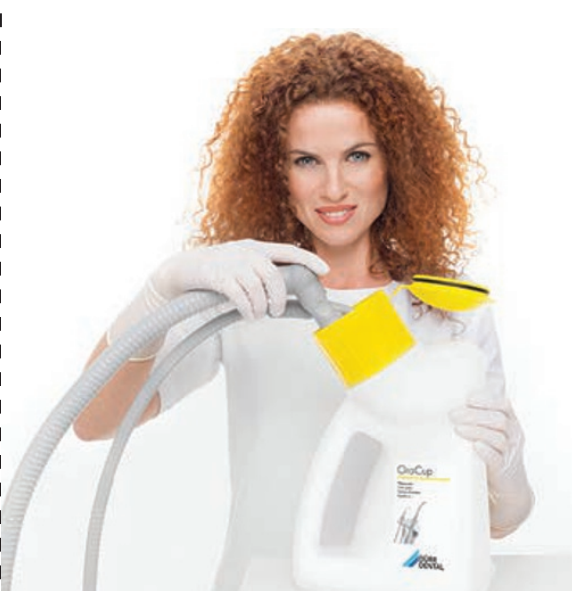

